\title{
A LITERATURA E AS PRÁTICAS DOCENTES: UM UNIVERSO A SER EXPLORADO
}

\author{
Simone Alves Pedersen (UNESP - Rio Claro) \\ Jussara Cristina Barboza Tortella (PUC - Campinas)
}

Resumo: Muito tem sido discutido sobre a importância da leitura, o baixo rendimento apresentado por estudantes brasileiros, e a literatura infantil como possibilidade de mudança dessa realidade. A Teoria Social Cognitiva (TSC) explica as dimensões psicológicas da aprendizagem com base na tríade: homem, ambiente e comportamento. Esse artigo aborda uma pesquisa-ação com um grupo de 12 professoras e 4 coordenadoras. Apresentaram-se estratégias de autorregulação da leitura que foram aplicadas em sala de aula pelas participantes. Após um ano, 3 professoras foram entrevistadas novamente. Resultados indicaram que houve mudanças nas práticas docentes das participantes, e um novo olhar em relação a seleção de obras literárias, que resultaram em maior compreensão leitora dos alunos, engajamento nas aulas e protagonismo em sua aprendizagem.

Palavras-chave: Literatura infantil; Estratégias de Leitura; Autorregulação da Leitura. Formação de Professores; Autorregulação da Aprendizagem.

\begin{abstract}
There has been much discussed about the importance of reading, the low performance presented by Brazilian students, children and youth literature (LIJ) as a possibility to change this reality. The Cognitive Social Theory (TSC), explains the psychological dimensions of learning, based on the triad: man, environment and behavior. This article addresses an action-research with a group of 12 teachers and 4 coordinators. Self-regulated reading strategies were presented and applied in the classroom by the participants. After one year, 3 teachers were interviewed again. Results indicated that there were changes in the teaching practices of the participants, and a new way of looking at the selection of literary works, which resulted in a greater reading comprehension of the students, engagement in the classes and protagonism in their learning.
\end{abstract}

Keywords: Children books; Reading strategies; Reading Selfregulation; Teachers Training; Learning Selfregulation. 


\section{INTRODUÇÃO}

Onde está o menino que eu fui?

Está dentro de mim ou se foi?

Sabe que jamais o quis

E que tampouco me queria?

Por que andamos tanto tempo Crescendo para depois nos separarmos?

Por que não morremos os dois Quando minha infância morreu?

E se minha alma se foi Por que me segue o esqueleto? (NERUDA, 2008, p.VLIV)

PabloNeruda (1904-1973), poeta chileno, ao aventurar-se pelo mundo infantil, no Livro das Perguntas, caminha entre dúvidas e incertezas, e nunca às responde. Essa postura de perguntar e não impor respostas trancadas é a postura que entendemos ser adequada aos professores - e a todas as pessoas, conforme afirmam Pedersen e Tortella (2015). As autoras refletem sobre o fato de que as sociedades estão em transformação, com uma rapidez nunca antes ocorrida na história da humanidade. Sem nos aprofundarmos na história do mundo, ao olhar apenas para os últimos 50 anos, temos o período da Ditadura Militar, que até há 30 anos ainda era realidade no Brasil. A Literatura nacional sofreu ainda mais censura nesse período, assim como todo tipo de comunicação, com o propósito de impedir o livre pensar. Foi nesse período que nasceu a Literatura Infantil brasileira. 
Em nosso país surgiu, então, timidamente, em um contexto de limitações políticas, iniciando com um grande apelo moralizante, a literatura para crianças. Usada como ferramenta de transmissão de saberes, serve de pretexto, de pílula silenciosa - ao contrário da pílula falante da personagem Emília de Monteiro Lobato, a boneca de pano, recheada de macela, que nasceu muda e após tomar uma pílula receitada pelo dr. Caramujo, passa a falar o tempo todo, falar o que pensa, sem autocensura. A literatura infantil surge como o remédio com gosto de morango, que, ao mesmo tempo em que o adulto oferece como doce, a criança engole e sente que não é saboroso, e que muito menos cria o interesse em uma nova dosagem. $E$ a criança passa a dizer que não gosta de remédio e, de tanto tomar remédio com gosto ruim de morango, passa a dizer que não gosta mais de morangos.

No século passado - mas não distante -, poucas escolas tinham biblioteca escolar ou livros infantis. Vivemos um período de transição. O governo fez investimentos maciços e, por meio do Programa Nacional da Biblioteca Escolar (PNBE), enviou livros - inclusive de literatura infantil - nos últimos anos, para todo o país.

Contudo, não houve uma formação prévia dos professores e gestores escolares sobre como aproveitar, de forma 
otimizada, esse acervo de alta qualidade que recebiam. Kramer e Souza (1996) comentam a precariedade das escolas nesse primeiro momento do PNBE e apontam para a questão crucial na mediação de leitura que vai além da didática e se fundamenta na apreciação literária do próprio mediador, como necessidade para que ele seja capaz de envolver os alunos na tarefa, sendo um efetivo modelo para seus alunos: "Muitas caixas ainda não foram abertas [...]. Como é possível a um professor ou a uma professora que não gosta de ler e de escrever, que não sente prazer em desvendar os múltiplos sentidos possíveis de um texto" (p.18).

A última edição da pesquisa Retratos da leitura no Brasil, realizada em 2015 e publicada em março de 2016 pelo Instituto Pró-livro, criado e mantido pelas entidades Associação Brasileira de Editores de Livros Escolares (Abrelivros), Câmara Brasileira de Livros (CBL) e Sindicato Nacional dos Editores de Livros (SNEL), que iniciou suas atividades em 2007 e possui como principal objetivo o fomento à leitura e a difusão e acesso ao livro, demonstrou que estamos, sim, caminhando na direção da formação de leitores em nosso país.

O brasileiro de 2011 lia uma média de 4 livros por ano e, em 2015, passou para 4,96. A porcentagem de livros lidos em partes subiu de 2 para 2,43 e a de livros inteiros, de 2,1 
para 2,43 . São resultados muito aquém do nosso objetivo, mas são resultados que demonstram um aumento e que não houve retrocesso nem estagnação.

Qual seria o motivo desses resultados? Decorrentes dessa questão, despontam outras dúvidas: qual seria o motivo de muitos dos nossos alunos não gostarem de ler? Qual seria o motivo de muitos dos nossos alunos não compreenderem o texto lido? Segundo Gimeno-Sacristán (2008), as práticas de leitura em sala de aula precisam ser mudadas: "O inimigo da leitura não reside, como actualmente alguns temem, [...] na extensão das novas tecnologias, mas nas desafortunadas práticas de leitura dominantes a que submetemos os nossos alunos durante a escolaridade" (GIMENO-SACRISTÁN, 2008, p.87).

Solé (1998) destaca a importância da atuação dos docentes para a melhoria da aprendizagem da leitura e do papel da leitura para a transformação dos conhecimentos. Para a autora, ler não é uma tarefa apenas para aprender (conteúdo), mas também para pensar, e a decodificação, apenas, não basta; afirma ainda que a fluência leitora necessita de exercício contínuo e que o leitor precisa aprender a interpretar textos com graus de dificuldade cada vez mais altos. 
Lajolo (2010) diz que "a discussão sobre leitura, principalmente sobre leitura numa sociedade que pretende democratizar-se, começa dizendo que os profissionais mais diretamente responsáveis pela iniciação na leitura devem ser bons leitores" (p.108). Os professores precisam conhecer estratégias de leitura, critérios de seleção de obras, literatura, e, serem leitores críticos, reflexivos, o que demanda uma compreensão leitora profunda.

Para fugir da linearidade, dos dualismos, dos estudantes que não questionam o mundo e o homem, surge a necessidade de uma escola que promova o dialogismo. Uma alternativa é a ampliação de experiências com a arte nas escolas e nas universidades, contemplando tanto a formação inicial quanto a formação continuada dos docentes, para que, sensibilizado, possa o professor sensibilizar. O homem que tem contato com a Arte desde o berço, amplia seus horizontes, aprende que a vida se entrelaça, que nada é fragmentado ou estático. Literatura é arte. Livros infantis sensibilizam leitores, os fazem rir, chorar, emocionar, pensar. Com o passar dos anos, o aluno se emociona com Padre Vieira porque ele o sente e compreende. Não existe compreensão sem que haja comunhão. Não existe contraponto sem que haja apropriação de saberes e opiniões múltiplas e consistentes. A Literatura é uma das ferramentas que pode 
promover o aprender, sensibilizando o leitor e o levando a, dialogicamente, refletir sobre o mundo e suas incertezas. Anjos e Vieira (2015) trazem a seguinte conclusão em sua pesquisa sobre a formação docente e a literatura infantil e suas contribuições para o desenvolvimento de leitores na Educação Infantil: "A pesquisa ajuda a inferir que os programas de formação continuada de professores precisam [...] trabalhar a Literatura Infantil e sua real implicação na prática pedagógica a partir das demandas do contexto, do professor e da sala de aula" (ANJOS; VIEIRA, p.320).

Pesquisas internacionais demonstram que a autorregulação da leitura, por meio do uso de estratégias de leitura sob a luz da teoria sociocognitiva, é um caminho promissor para a promoção de leitores competentes e críticos. Todavia, estudos sobre a autorregulação da leitura praticamente inexistem em nosso país.

Considerando que a literatura infantil tem sido objeto de muitas pesquisas na formação do leitor e tem gerado interesse em diversas áreas, partiu-se do pressuposto de que os procedimentos utilizados pelos docentes e a seleção de obras são elementos essenciais para a formação do leitor.

A pesquisa de mestrado aqui apresentada, A Formação Continuada de Professores e a Literatura: estratégias de 
leitura e seleção de obra, propôs por problema de pesquisa a seguinte questão: a exploração de estratégias de leitura e seleção de obras, em um curso de formação continuada, pode auxiliar os professores participantes em seu trabalho com leitura?

O objetivo geral foi verificar se houve mudanças na prática dos professores sobre a exploração de modos de leitura, estratégias de leitura e seleção de obras no trabalho com leitura. Os objetivos específicos foram implementar um modelo de formação continuada em leitura, apresentar a autorregulação da leitura, discutir a seleção das obras literárias e analisar em que medida as participantes aplicaram o conhecimento construído na formação.

A metodologia adotada nessa pesquisa qualitativa com princípios da pesquisa ação-estratégica constituiuse, inicialmente, de levantamento bibliográfico nacional e internacional. Ministrou-se um curso de formação continuada para 12 professoras e 4 coordenadoras da rede municipal de um município do estado de São Paulo.

Durante os 4 encontros formativos, na escola do servidor público municipal, no total de 9 horas, apresentaramse a leitura independente, leitura em dupla, close reading e outras estratégias de leitura, a partir dos pressupostos 
teóricos da autorregulação, pautados nos estudos da TSC. Os instrumentos utilizados foram: diário de campo, questionário, narrativa e entrevista semiestruturada.

As entrevistas ocorreram no início ou no final dos encontros, com perguntas sobre o que esperavam da formação, o que poderiam fazer para conhecer novas estratégias de leitura e obras infantis, e se a formação estava contribuindo para uma reflexão sobre as práticas de leitura em sala de aula. As narrativas foram produzidas durante o último encontro, simultaneamente.

As participantes da pesquisa aplicaram o conteúdo dos encontros formativos, em sala de aula. Houve troca de experiências sobre leitura e uso de obras literárias durante os encontros, que possibilitaram o pensar e repensar práticas, ouvir sobre a experiência de outros professores e narrar sucessos e desafios que fazem parte da docência e da leitura. Após um ano da formação, 3 participantes indicadas pela secretaria da educação, por critérios de disponibilidade, foram novamente entrevistadas. Nessa nova entrevista, perguntou-se o que a professora pensava hoje sobre a formação ocorrida no ano anterior, se ela aplicava alguma das práticas de leitura e seleção de obras com a classe desse ano, qual prática ela havia gostado mais, se havia alguma prática 
que não havia gostado ou achava que não era interessante e se havia alguma outra observação que gostaria de fazer.

Os dados coletados por meio de questionários, narrativas, caderno de campo e entrevistas semiestruturadas foram analisados a partir dos princípios da análise de conteúdo, pelos seguintes eixos: seleção de livros antes da formação; práticas de leitura antes da formação; expectativas de aprendizagem; aprendizagens durante a formação; mudanças durante a formação; reflexão sobre a formação após um ano; aplicação das práticas após a formação; estratégias que mais gostou; mudanças nas práticas de leitura, mudanças na concepção do professor.

\section{A TEORIA SOCIAL COGNITIVA (TSC)}

A TSC foi desenvolvida pelo psicólogo canadense Albert Bandura (1968), que hoje atua como professor na Universidade de Stanford. Bandura é hoje, um dos mais citados psicólogos do mundo, ao lado de Skinner, Freud e Piaget, apesar de pouco conhecido em nosso país. Ele afastou as teorias baseadas em dualismos e apresentou a possibilidade de o homem afetar e ser afetado pelo ambiente, pelas suas próprias crenças e pelo cognitivo. Em sua complexa teoria, ele apresenta as duas formas de aprendizagem: experiência direta e experiência vicária. Autor do famoso experimento sobre a agressividade 
aprendida, com o boneco João-bobo, o psicólogo tem se aprofundado nos mecanismos psicológicos envolvidos no comportamento humano, inclusive na aprendizagem.

Pelo modelo cíclico da reciprocidade triádica, Bandura afasta o dualismo de outras teorias psicológicas e explica o comportamento humano como resultado de fatores comportamentais, pessoais e ambientais, que se interafetam. Demonstra assim, que o comportamento humano é influenciado pelas nossas crenças, pelas nossas experiências, pelas circunstâncias, pela nossa capacidade de processamento cognitivo das situações, entre outros fatores, em um mosaico de subprocessos psicológicos que afetam as nossas escolhas e comportamentos.

Pela tríade recíproca do funcionamento humano, as contribuições pessoais, comportamentais e ambientais influenciam o comportamento humano separada, mas interdependentemente (ZIMMERMAN, 2009).

Bandura (1989) anuncia que são quatro as capacidades humanas que possibilitam que o sujeito seja agente e capaz de escolher e construir sua própria trajetória: Intencionalidade: o sujeito determina uma meta e se compromete em atingila; Antecipação: por processo cognitivo, o sujeito antecipa o resultado de seu comportamento em relação à meta 
estabelecida; Autorregulação: o sujeito monitora, avalia e controla seu comportamento e pensamento, em relação à meta estabelecida; Autorreflexão: o sujeito reflete e analisa seu comportamento e pensamentos, organizando suas percepções e readequando seu comportamento em relação às metas.

A Teoria Social Cognitiva de Albert Bandura considera a capacidade de autorregulação uma das características centrais da agência humana. Essas quatro capacidades humanas fundamentais permitem que o sujeito seja capaz de proativamente decidir como viver sua vida, como comportarse, como autorregular-se e promover as mudanças necessárias para atingir seus objetivos, inclusive obter melhoria e sucesso em seu desempenho acadêmico. Vemos, então, um sujeito que é agente, que toma decisões, que não está condenado ao fracasso pelo ambiente ou por limitações do cognitivo (BANDURA, 1989).

As pessoas têm a capacidade de antecipação pela qual podem planejar ações que as ajudem a transpor os obstáculos existentes. Elas também têm a capacidade decisória sobre o grau de importância dado às informações geradas nas situações, se as usam, como as usam, onde e com quem as usam. 
A autorregulação é uma possibilidade comportamental que pode ou não ocorrer. Para que aconteça, é necessário que o sujeito possa ter certo grau de controle. Se o controle for externo, não há que se falar em "auto"rregulação. A TSC propõe um sistema de duplo controle na autorregulação um sistema proativo de produção de discrepâncias com um sistema reativo de redução de discrepâncias (BANDURA, 1989).

Os pilares da autorregulação são três subfunções psicológicas (BANDURA, 1989), que são passíveis - não ocorrem espontaneamente - de controle humano: a) autoobservação; b) processos de julgamento e c) autorreações.

No contexto educacional, podemos trabalhar a autorregulação da aprendizagem desde a primeira infância. Um aluno autorregulado não significa um aluno sem criatividade. A autorregulação da aprendizagem é um processo que ajuda o aluno a organizar-se, estabelecer metas, identificar suas dificuldades, buscar ajuda, transpor dificuldades, e, atingir o sucesso escolar.

Zimmerman (2002) diz que as habilidades que perfazem o processo de autorregulação da aprendizagem são: a) determinar objetivos próximos, b) adotar estratégias eficientes para alcançar os resultados, c) monitorar o 
desempenho identificando sinais de progresso, d) reestruturar o contexto ambiental e social para que seja adequado ao objetivo estipulado, e) gerenciar o tempo eficientemente, f) autoavaliar os métodos empregados, g) atribuir causa aos resultados e h) adaptar métodos para usos futuros.

A participação do aluno no planejamento de atividades e estabelecimento de objetivos é fundamental para que a aprendizagem seja autorregulada, segundo Rosário et al (2001). Quando as decisões sobre o que, como, quando e onde aprender são tomadas por outros, o aluno não tem controle, e autorregulação implica controlar as condições envolvidas na aprendizagem.

O professor pode intervir no processo de aprendizagem do aluno, ao ensinar estratégias de aprendizagem que possam equipá-lo para um estudar com mais competência. Ao estudar com mais competência, o aluno terá um desempenho acadêmico de sucesso que afetará sua autoeficácia e motivação.

O nível de aprendizado do aluno depende não tanto de suas habilidades, quanto de seu domínio sobre os processos autorregulatórios (ZIMMERMAN, 2002).

Em relação à leitura, o professor pode ampliar suas práticas pedagógicas, diversificar os modos de ler, ensinar estratégias que ajudem os alunos a ter uma maior compreensão do texto lido. 
A leitura não é apenas decodificação, não é apenas deleite, não é uma atividade simples. Momentos felizes, momentos de sucesso na sala de aula, competência leitora, fruição de um texto literário, ser respeitado pelo professor e colegas, todas essas experiências afetam positivamente a autoeficácia do aluno, um dos constructos mais importantes da TSC. Motivam a realização das tarefas: "quanto mais sucesso eu tenho, mais motivado a repetir a ação, mais prezo aquele tipo de ação!", concretiza, sem necessariamente verbalizar, o aluno. E para ter sucesso na leitura e compreensão do texto lido, estratégias de leitura podem ser uma ferramenta eficaz.

Os alunos, ao aprenderem, também desenvolvem estratégias de aprendizagem com o objetivo de facilitar e melhorar a aquisição de conhecimentos, em um movimento metacognitivo. Esse comportamento é autorregulador: exige planejamento, acompanhamento e avaliação, adaptação, identificação de dificuldades, escolha da forma de ajuda mais adequada - e a leitura pode ser uma excelente ferramenta para a autorregulação da aprendizagem.

\section{A AUTORREGULAÇÃO DA LEITURA}

A autorregulação do comportamento humano tem sido estudada há mais de 40 anos (SCHUNK, 2001; CASH, 2016), sob variados marcos teóricos. As teorias denominadas como 
operante, fenomenológica, do processamento de informação, sociocognitiva, motivacional, construtivista e vygotskiana consideram a autorregulação sob diferentes visões no que tange à motivação, autoconsciência, processos-chaves, ambiente social e físico, bem como capacidade de aquisição de novos conhecimentos, segundo Zimmerman (1989).

O conceito de autorregulação ou aprendizagem autorregulada é definido, no âmbito da perspectiva sociocognitiva, como os pensamentos, sentimentos e ações gerados pelo próprio sujeito, os quais são planejados e sistematicamente adaptados às necessidades, a fim de atuarem sobre a própria aprendizagem e motivação (SCHUNK, 2001; ZIMMERMAN, 1989; ZIMMERMAN, 2002). Os alunos autorregulados são motivados, independentes e participantes ativos de sua aprendizagem (ZIMMERMAN, 1989, 2002; ZIMMERMAN; BANDURA,1994; ZIMMERMAN; MARTINEZ-PONS, 1988).

Existe uma associação significativa entre compreensão leitora e desempenho acadêmico. A fraca compreensão da leitura promove dificuldades em aprendizagem que estimulam a ausência ou ineficácia de hábitos de estudos (SANTOS; SUEHIRO; OLIVEIRA, 2014).

Para Boruchovitch (1999), os problemas educacionais brasileiros necessitam de soluções que transcendam as 
metodologias pedagógicas, e o país carece de mudanças políticas, socioeconômicas e culturais, embora não se possa negar que temos também uma incapacidade de ensinar. Assim sendo, é imprescindível que os professores ampliem seus repertórios de estratégias de aprendizagem para ter variadas ferramentas disponíveis às diversas necessidades que a docência apresenta, com alunos, por sua vez, singulares em suas necessidades.

O baixo desempenho em leitura e escrita leva ao baixo desempenho acadêmico, e o baixo desempenho acadêmico está relacionado com a evasão escolar. Segundo pesquisa da Fundação Getúlio Vargas de 2009, intitulada Motivos da Evasão Escolar, 30\% dos estudantes com as piores notas no nível fundamental sequer se matriculam no ensino médio.

Zimmerman (2002, p.65) destaca que "a rigidez do curriculum escolar causa efeitos indesejáveis na autoeficácia de alunos que apresentam dificuldades em compreender e reter informações. Não é incomum que esses alunos sejam pouco motivados". Segundo o autor, quando o curriculum é definido por idade ou nível de aprendizado, não há flexibilidade para acomodar as diferenças individuais. Isso significa que mesmo crianças com dificuldade em aprendizagem podem superar desafios em relação à leitura se autorregularem seu comportamento. 
Por exemplo, alunos pequenos muitas vezes leem em suas camas, ou no sofá, enquanto assistem televisão ou olham o celular. Ao planejar um momento de leitura, o ambiente escolhido é primordial. Afastar chamamentos externos, como desligar o telefone, fechar a porta para o animal de estimação não entrar, podem favorecer a concentração necessária para a leitura. Nem sempre alunos consideram a relevância dos fatores ambientais envolvidos na execução da tarefa. Também é importante que os alunos saibam que são capazes, o que não significa que não encontrarão desafios, mas sim, que a leitura não deve ser abandonada quando apresenta dificuldades, existem estratégias que podem ajudar o aluno a compreender melhor o que lê.

\section{A LEITURA EM SALA DE AULA: LEITURA INDEPENDENTE}

Durante os quatro encontros da formação, apresentamos as seguintes estratégias e modos de leitura, com o objetivo de ampliar o repertório das professoras de práticas docentes que promovessem uma leitura proficiente.

Independente é a leitura que os alunos escolhem fazer sozinhos, refletindo a escolha pessoal do material que será lido, assim como onde e quando. Pode ser por deleite ou ter um caráter informativo. Ninguém solicita, ninguém espera um relatório, ninguém verifica se houve compreensão. 
Também é conhecida como leitura voluntária, leitura no tempo livre, leitura recreacional (CULLINAN, 2000).

Pesquisas relatam que alunos não escolhem ler muito de forma independente, bem como não o fazem com frequência (GREANEY, 1980; ANDERSON, FIELDING, WILSON, 1988).

Morrow e Weinstein (1986), em vários estudos, encontraram pouquíssimas crianças pré-escolares ou no ensino fundamental que escolhessem olhar livros ou lê-los em seu tempo livre. Os anos pré-escolares são cruciais no desenvolvimento literário e da linguagem (DURKIN, 1966; CLAY, 1991). Greaney (1980) relatou que apenas 5,4\% do tempo livre era usado em leitura por alunos de quinto ano que ele pesquisou, sendo que $23 \%$ desses alunos preferiam não ler absolutamente nada em seu tempo livre.

Kasten e Wilfong (2007) relataram que tiveram alunos no Ensino Médio que chegaram com desempenho leitor muito baixo, assim como um diretor escolar que proibia leitura independente em classe, pois considerava desperdício do tempo.

Apesar da literatura largamente associar leitura com desempenho acadêmico, os resultados das pesquisas mencionadas indicam que o modo como ler que está sendo ensinado na escola não produz leitores independentes 
(CULLINN, 2000). Irving (1980) fez um estudo para a UNESCO, em que os sujeitos pesquisados majoritariamente não fizeram nenhuma ligação entre ler e prazer.

Kasten e Wilfong (2007) fazem uma analogia em relação ao desempenho leitor e desempenho esportivo:

A leitura independente é como o tempo que os atletas necessitam para se tornarem bons no esporte que praticam, ou o tempo que músicos precisam para se tornarem bons com aquele instrumento. Todas as habilidades necessitam tempo de prática. Além do que, fortalece a confiança e habilidade que ajudam os alunos lerem textos cada vez mais sofisticados. (p.2)

O domínio de habilidades eleva a autoeficácia e são necessárias ambas para um desempenho de sucesso (BANDURA, 1997). Em relação à competência leitora e autoeficácia do leitor para ler livros mais desafiadores, Clay (1991) diz que oportunidades consistentes de leitura independente ajudam a desenvolver a fluência leitora, assim como melhoram a confiança do leitor em ler livros mais sofisticados.

Aleitura independentetambém promovea autorregulação: o aluno precisa definir sua meta (ler um livro), escolher o livro (executar a meta a partir de uma escolha), decidir como 
lerá o livro (onde lerá, como controlará os chamamentos externos, iluminação, posição, se usará estratégias de leitura, que material precisa - óculos, marca textos, post-it etc).

\section{LEITURA EM VOZ ALTA}

Ler em voz alta para alunos é um importante componente de um programa literário, pois é uma oportunidade de motivar os alunos, desenvolver interesses literários, modelar fluência leitora, engajar alunos na discussão e análise do texto, além de demonstrar estratégias de leitura (RICHARDSON, 2009).

Crianças pequenas para as quais foram lidas histórias desde bebês, segundo Gambrell, Morrow e Pennington (2002), sabem identificar a capa do livro, onde fica o título, o que deve ser lido, muito antes de aprenderem a ler.

Várias pesquisas experimentais que investigaram os efeitos da leitura em voz alta pela professora para a classe como uma prática habitual apresentaram desenvolvimento leitor com melhor desempenho do que crianças para as quais professores não leram histórias. Vocabulário, compreensão e inferência tiveram melhores resultados para essas crianças (GAMBRELL, MORROW, PENNINGTON, 2002; GREEN, HARKER, 1982; ROSER, MARTINEZ, 1985).

Se além de quem lê em voz alta, todos os alunos tiverem uma cópia do texto e acompanharem a leitura que ouvem, 
lendo simultaneamente, será uma leitura chamada de compartilhada (RICHARDSON, 2009).

Não obstante, as pesquisas que comprovam os benefícios da leitura em voz alta pelo professor e por alunos sugerem que ouvir uma leitura não é uma atividade mágica que tem efeitos positivos e imediatos (GREEN, HARKER, 1982). A qualidade dessa interação é que promove os benefícios, e, segundo esses autores, não é comum que professores tenham formação suficiente para essa prática pedagógica.

O estilo da leitura em voz alta e das atividades subsequentes afetam a compreensão do texto pelo aluno (GREEN, HARKER, 1982). Vários estudos foram efetuados para entender essa relação entre a leitura em voz alta e a compreensão dos alunos. Para Greaney (1980), grupos pequenos tiveram maior compreensão do que em histórias lidas pela professora individualmente para cada aluno. Já grupos maiores tiveram compreensão bem inferior aos que tiveram a história lida individualmente.

A leitura em voz alta é uma fonte de autoeficácia (experiência direta para quem lê e experiência vicária para quem ouve). Ajuda o aluno a enfrentar o desafio de ler para outras pessoas, alimentar sua autoeficácia com seus sucessos e ajuda-lo a enfrentar e superar suas dificuldades. 


\section{LEITURA EM PARES}

Pesquisas indicam que alunos com dificuldades em leitura, quando leem em conjunto com um aluno que tenha melhor desempenho leitor, ganham substancialmente em reconhecimento de vocabulário e fluência leitora (SNOW; GRIFFIN, 2005).

Segundo Cassidy (2007), as escolas não dispõem de recursos humanos suficientes para atender à necessidade de alunos com dificuldade em leitura, e a leitura em pares, com o treinamento dos alunos-tutores, é uma saída que beneficia a todos: professores, alunos com dificuldades e alunos-tutores, que se sentem orgulhosos de poder ajudar e praticam leitura também. Para a autora, a escola moderna inclui a família no aprendizado, outros alunos e tutores provenientes da comunidade, com notório saber, para dar conta de atender ao grande número de alunos e limitado número de professores (CASSIDY, 2007).

A leitura em pares é um método que envolve a escolha de pares com níveis diferentes de competência leitora. Eles leem um texto em voz alta, juntos. A leitura é controlada pelo leitor com mais fluência, que diminui a velocidade quando o aluno aprendiz demonstra dificuldades em alguma passagem. O leitor com menor fluência faz a leitura sozinho 
em trechos que ele se sinta confiante, sinalizando seu desejo para seu colega tutor (GRIFFIN, 2005; CASSIDY, 2007). Para Cassidy (2007), a leitura em pares pode ser usada com qualquer tipo de texto: aqueles produzidos pelos próprios alunos, informativos, de ficção, poesia etc.

Na leitura em pares, o professor é modelo para os pares. Porém, cada aluno é modelo para o seu parceiro. Portanto, se o modelo for de competência muito acima do nível do observador, ele pode não produzir os resultados esperados. Desse modo pode ser com um aluno que tenha um nível leitor um pouco acima do outro (DUKE, PEARSON, 2002).

A modelação do professor é fundamental na leitura em pares. Os melhores exemplos de como agir na leitura em pares são demonstrados pelo professor, como pronunciar as palavras de forma correta quando um aluno tem dificuldade, modular a entonação, elogiar quando o aluno lê bem etc (CASSIDY, 2007).

Na leitura em pares, o aluno aprende por observação, mas ele também exerce sua autorregulação ao controlar seu comportamento e não desviar a atenção para os outros pares. Sua autoeficácia é alimentada pela fonte da persuasão social, pelo feedback que ele recebe e como ele reage: aproveitando-o para melhorar ou sentindo-se desmotivado 
por ter sido criticado. Nesse movimento, a modelação ocorre o tempo todo em sala de aula, pelo professor ou pelo aluno ao lado, ou ainda, pelos colegas de outras salas, funcionários e gestores de uma escola. A autorregulação do comportamento e da aprendizagem se faz presente o tempo todo no contexto escolar. Em todas as tarefas, ao estabelecermos objetivos, planificarmos como atingi-los, ao controlarmos o ambiente e os chamamentos externos, executamos ações que acreditamos nos levar ao sucesso.

\section{CLOSE READING}

Nos Estados Unidos, The Common Core State Standards (CCSS) - que são os padrões adotados por mais de 46 estados americanos, com o objetivo de melhorar o ensino e a aprendizagem, em um ambicioso programa que pretende elevar os níveis padronizando o núcleo dos objetivos, mas permitindo que cada estado faça seus ajustes de acordo com as necessidades locais - selecionou o close reading como o melhor método para aprimorar a compreensão leitora dos alunos de todos os tipos de leitura, desde as pequenas crianças até os estudantes no final do ensino médio, melhorando a capacidade e a formação universitária destes. O rol de padrões foi elaborado com a participação de professores e pesquisadores de vários países, com base 
nos melhores índices nacionais e internacionais, e tem como objetivo preparar alunos para o Ensino Superior, carreira e família (HINCHMAN; MOORE, 2013).

Hinchman e Moore (2013) entendem que, no close reading, a ênfase é uma atenção diligente focada no texto e nada mais que o texto, que é uma entidade autônoma; leitores interpretam o significado dentro dos limites que o texto oferece. Por exemplo, conectar o texto com a vida do autor ou contexto histórico não seria permitido.

Com o passar do tempo, alguns teoristas literários mudaram a forma como close reading era usado e passaram a adotar a leitura com foco nos objetivos e modos de compreender os textos, como transformar o sentido de um texto de acordo com a experiência de cada leitor (ROSENBLATT, 1978) ou de acordo com normas de um método de interpretação específico (FISH, 1982). Essa abordagem foi depois aceita e adotada nas escolas de Ensino Médio, nas aulas de língua nativa - inglês - nos anos 1950 e 1960, segundo Sperling e DiPardo (2008).

A Teoria Crítica Literária promove o close reading como uma ferramenta para identificar o discurso embutido em um texto em relação a raça, classe, gênero e outras marcas sociais (APPLEMAN, 2009). Para os desconstrutores, o close reading 
permite analisar os diferentes, e muitas vezes contraditórios, significados que um texto traz, porque segundo eles, as palavras não têm um significado fechado e definido.

Sisson e Sisson (2014) afirmam que houve uma mudança drástica no ensino da leitura, ao trazer de volta o close reading como cerne do novo programa educacional norteamericano, abandonando a ativação dos conhecimentos prévios e as conexões como estratégias de compreensão leitora. As autoras dizem que "o close reading oferece um método confiável para os estudantes examinarem textos de modos significativos" (p.31).

Lehman e Roberts são pesquisadores da Faculdade de Educação da Universidade Columbia, no Projeto Ler e Escrever. Os autores dizem que o close reading deve aumentar o engajamento e o deleite, não diminuí-lo; tem de guiar os estudantes para a independência, não dependência e incitamento do professor; tem de ser uma parte do ensino de leitura, não a única parte da sua aula; tem de disponibilizar tempo para os alunos lerem por períodos longos as várias páginas do texto, sem interromper o tempo de leitura com atividades; deve ser repetido durante o curso e envolve muitas oportunidades para prática, não uma atividade da lista a ser eliminada com uma única aplicação; deve ser 
alinhado com as capacidades e limitações dos seus alunos, não planejado para alinhar-se com um livro ou se encaixar a uma oportunidade ou sequência didática (LEHMAN, ROBERTS, 2013).

"Close reading, então, não deve implicar que nós ignoramos a experiência do leitor e focamos apenas no texto e nada mais. Deve implicar que nós trazemos o texto e o leitor mais próximos", afirmam Beers e Probst (2007, p.31), explicando que ignorar uma dessas duas posições faz da leitura uma tarefa impossível.

Beers e Probst (2013) trazem um roteiro com uma lista de tópicos para close reading, que servem de guia para anotações dos alunos, em leituras de textos ficcionais: a) Contraste e contradições: mudanças de comportamento dos personagens. Ajuda alunos a perceberem o desenvolvimento do personagem, conflitos internos, assim como as relações dos personagens principais do enredo; b) Momento SURPRESA: é quando o personagem faz ou descobre algo que ele não sabia antes. Ajuda os alunos a entenderem as ações do personagem e a sua relação com o conflito, o desenvolvimento do enredo, e, às vezes, o tema; c) Perguntas difíceis: em algum ponto da narrativa, o personagem principal coloca em palavras o problema que ele ou ela está 
enfrentando. Trata-se de uma questão, de um problema que não é uma pergunta simples e o aluno deve se perguntar "O que esta pergunta me faz pensar?"; d) Palavras do sábio: as palavras do sábio ajudam o aluno a identificar o tema da narrativa. Normalmente, vem como um conselho de um personagem mais velho e é dirigido ao personagem principal; e) De novo e de novo: ajuda os alunos a se manterem alertas às repetições que ocorrem em um texto, muitas vezes, separadas por páginas, mas que certamente querem deixar um ponto claro; f) Momento memória: ajuda os alunos a reconhecerem lembranças de algo que aconteceu antes, o que normalmente tem relevância para o desenrolar dos acontecimentos atuais da história.

O close reading é um método que engloba estratégias de sublinhar, marcar o texto, fazer anotações e releituras que sanem todas as possíveis dúvidas que possam ocorrer durante a leitura. O foco é a busca de evidências no próprio texto, para que o aluno tenha subsídios para interpretar o que leu. Não obstante o close reading buscar o sentido que o autor dá ao texto, não ignora a subjetividade do leitor. Todavia, ao ter evidências nos textos para responder perguntas sobre o texto, o aluno não formula respostas baseadas em "achismos" e pode apresentar seu ponto de 
vista contrapondo ou concordando com o autor, trazendo seu conhecimento prévio, suas experiências, sem relevar o que o autor pensa.

\section{ANTECIPAÇÃO}

A antecipação ocorre com a observação do título do livro, os capítulos, o autor, ilustrador etc. Para Solé (1998), a leitura deve começar pela observação genérica do livro. Frison afirma que essas observações influenciam o comportamento do leitor:

O uso dessas estratégias pode determinar o modo como o estudante se comporta diante de um texto e controla a consecução do seu objetivo. Assim, ao empregarem estratégias de antecipação da leitura, os alunos traçam um plano estratégico em que planejam as ações que irão nortear a consecução do seu objetivo. (2016, p.9)

A antecipação ajuda na formação do leitor, que cria familiaridade com os livros que lê, tornando-se capaz de identificar semelhanças e diferenças entre autores de texto e imagens (PEDERSEN, no prelo).

\section{ATIVAÇÃO DE CONHECIMENTOS PRÉVIOS}

Schliesman (2012) considera que os leitores usam o que já sabem (ou pensam que sabem) antes, durante e 
depois da leitura para clarificar seu entendimento lou desentendimento) do texto. Para Solé (1998), o leitor que aciona conhecimentos prévios efetua uma leitura crítica quando analisa o que lê e o compara com o que ocorre no mundo.

Para Sisson e Sisson (2014), o conhecimento prévio é o que alguém sabe sobre um assunto e reflete o que o leitor traz para o texto para incrementar sua compreensão. As autoras sugerem que o conhecimento prévio de um assunto é, em última instância, o melhor indicador da habilidade dos alunos em adquirir novos conhecimentos.

Simões e Souza afirmam que a estratégia de ativação dos conhecimentos prévios é uma estratégia "guarda-chuva": "A todo momento o leitor ativa conhecimentos que já possui com relação ao que está sendo lido. Assim, antes de ler, as crianças geralmente acionam conhecimentos prévios que podem estar relacionados às ideias do texto" (SIMÕES; SOUZA, 2011, p.15). Segundo as autoras, uma pré-leitura rápida por todo o texto muitas vezes resulta em formular hipóteses com base nos conhecimentos que o leitor já tem. A formulação de hipóteses, quando se começa a ler um texto, é o primeiro passo para compreendê-lo, mesmo que as hipóteses não sejam confirmadas ao adentrar o texto com mais profundidade (SIMÕES; SOUZA, 2011). 
Fountas e Pinnell (2001, p.306) exemplificam da seguinte forma: "se você visitou um lugar em particular e depois lê sobre ele em um romance histórico que se passa naquele lugar, você vai expandir a compreensão, ou pelo menos, terá significados diferentes para a história que lê".

\section{CONEXÃO}

Para os autores Smith (1999) e Solé (1998), explora-se o texto por meio das conexões que o leitor faz em nível pessoal, intertextual e com o mundo. Ao fazer conexões, o texto se modifica e encontra uma interpretação que pode ser diferente para cada leitor.

A conexão consiste em ligar o que lemos com algo semelhante que já sabemos. Para Simões e Souza (2011, p.15), "relembrar fatos importantes de sua vida, de outros textos lidos e de situações que ocorrem no mundo, em seu país ou cidade, ajuda a compreender o texto em questão".

Para Schliesman (2012), os leitores relacionam o texto com experiências, pessoas, informações de outros textos e informações sobre o mundo para ampliar a compreensão textual.

Fountas e Pinnell (2001, p.359) sugerem que os professores, para ajudarem seus alunos a se tornarem leitores que façam conexões ativamente: a) socializem com eles suas próprias 
conexões entre suas leituras e vida pessoal, seu conhecimento do mundo e dos temas envolvidos, e outros textos com temas similares, cenários e personagens do mesmo autor; b) mostrem para seus alunos como você fez as conexões; c) estimulem seus alunos a fazerem conexões com suas próprias experiências, outros textos lidos e conhecimentos prévios; d) deem feedback positivo quando eles compartilharem suas experiências, trouxerem conhecimentos prévios ou mencionarem textos similares ou que eles já tenham lido; e) observem as conversas dos alunos entre si e com eles, docentes, para identificar a extensão das conexões estabelecidas.

Simon (2016, s/n) indica perguntas que os professores podem fazer aos alunos para ajudá-los a estruturar as suas próprias:

1) conexões do texto: O que esta história o faz lembrar? Você faz algo parecido com esses personagens? Algo dessa história o faz lembrar de algo em sua vida? 2) Conexões literárias: O que você leu o faz lembrar de algum outro livro? Como esse livro se parece com outros que você leu? Como esse texto é diferente de outros que você leu? 3) Conexão com o mundo: O que essa história o faz lembrar do mundo real? Como os acontecimentos dessa história se parecem com acontecimentos do mundo real? Como eventos dessa história são diferentes de acontecimentos do mundo real? 
A conexão pode nos levar a fazer ligações que conduzam o texto para uma significação mais pessoal. Por exemplo, um texto que traz um veterano de guerra pode ter significados diferentes para o leitor que é veterano e vivenciou a guerra e para um terrorista. A conexão também pode ampliar a compreensão ao fazermos ligações com informações adicionais. Por exemplo, um personagem de uma história que é maratonista pode ser compreendido de forma mais profunda por alguém que participou de uma maratona, ou por alguém que conheceu e acompanhou o treinamento de um maratonista.

Uma criança que mora no interior terá mais facilidade em fazer conexão com um personagem que vive no campo, do que outra que vive em uma capital, e vice-versa.

A experiência direta não é a única forma de conhecimento. Temos a aprendizagem vicária e podemos conhecer previamente assuntos por meio de leituras, programas de televisão, internet etc. Quando a conexão é feita entre textos, chama-se intertextualidade.

A intertextualidade está na associação de outras histórias com a história lida, ou com pequenas histórias já existentes inseridas dentro de uma história mais extensa. Por meio da intertextualidade, o leitor amplia aquele trecho da história, 
trazendo suas memórias da outra história ali contida. Por exemplo, ao ler a história de Kaspar Hauser, o menino que foi criado sem contato social até os 15 anos, podemos fazer uma conexão com a história do Mogli, o menino que foi criado por lobos e que é um personagem simbólico. Trata-se de uma conexão porque há similaridades, mas em nenhuma das duas histórias a outra é citada.

Em uma história como a do Lobo Mau, se a Chapeuzinho Vermelho, ao passear pela floresta, encontrasse sete anões cantando, a caminho do trabalho, seria um exemplo de intertextualidade. Amplia-se a história com a participação de personagens de outras.

\section{INFERÊNCIAS}

“Inferências são conhecimentos trazidos pelo leitor durante (ou após) o processo de leitura. Esses conhecimentos podem servir [...], para enriquecer o texto que se está lendo, para conectar diferentes ideias entre elas ou para gerar ideias de resumo", segundo Fountas e Pinnel (2012, p.367).

"Inferir é ultrapassar o sentido literal de um texto, ir além, alcançar o que está implícito. Para inferir, usamos as conexões que fizemos para formular hipóteses e criar imagens sensoriais", segundo Fountas e Pinnell (2001, p.361). Os autores sugerem que os professores podem ensinar seus 
alunos a inferirem, quando: solicitam que os alunos pensem sobre o autor e outros livros que ele escreveu; perguntam o que eles sabem sobre o contexto histórico; pedem aos alunos para tentarem adivinhar o que está implícito em certas passagens.

Inferir é concluir com base em alguma informação validada, quando o texto não a traz explicitamente. É a leitura do que não está dito, mas que tem pistas no texto que levem o leitor a essa conclusão. Por exemplo, um personagem que marca um encontro com outro personagem, em uma história, sendo o segundo um assassino conhecido, nos leva a inferir que o primeiro quer contratá-lo para assassinar alguém. É uma hipótese que pode ou não se confirmar, mas não é uma hipótese sem uma base sólida: pessoas não se encontram com assassinos reconhecidos sem ter uma intenção. Por outro lado, se um personagem marca um encontro com um assassino que ele sabe ter tirado a vida de uma pessoa que ele conhecia, pode-se inferir que ele queira vingança. A inferência não acontece sem que o autor deixe pistas no texto para que o leitor as colecione.

\section{VISUALIZAÇÃO}

Solé $(1998$, p.108) afirma que somos capazes de antecipar e prever o que será abordado nas próximas páginas de um 
livro. Nem todas as pessoas se sentem à vontade para fazêlo, já que "formular hipóteses, fazer previsões exige correr riscos, pois por definição não envolvem a exatidão daquilo que se previu ou formulou". É uma oportunidade de exercitar a imaginação e expandir a história lida em um movimento de criação, contribuindo para a formação do aluno escritor. Tanto na visualização quanto na antecipação, a imaginação da criança é ativada e, consequentemente, desenvolvida.

Para Schliesman (2012), o leitor cria imagens em sua mente que refletem ou representam as ideias lidas para ajudar na compreensão do texto.

A visualização pode ocorrer de forma espontânea ou não. Mesmo que haja a intenção de visualizar um objeto, ser ou cenário, cada pessoa tem a sua própria visualização. Na falta de ilustrações ou fotografias, nossa mente tem a capacidade de criar imagens para o que lemos. Essas imagens serão formadas com base em nosso conhecimento prévio, em nossas experiências ou seguindo as instruções de alguém.

Para Fountas e Pinnell (2001, p.361), "Visualizar faz com que a leitura se torne viva" por meio de imagens sensoriais. Ao visualizar o lugar descrito no texto, segundo as autoras, o leitor sente que está lá. Da mesma forma, ele pode sentir que conhece os personagens - como eles são, sua voz, sua aparência. 
Por exemplo, ao visualizar um castelo medieval, alguns podem lembrar dos castelos mais antigos, sem nenhum conforto, frios, nos quais havia pouco mobiliário e uma câmara de tortura para os inimigos. Também podemos pensar em outros castelos, com torres altas como nos contos de fadas, em particular aquele onde Rapunzel ficou cativa.

Algumas crianças podem imaginar o Castelo da Cinderela, em sua versão animada pela Disney, enquanto as moças românticas podem visualizar o real Castelo de Neuschwanstein na Baviera, Alemanha, que foi a inspiração do castelo da Cinderela. Ou pode, ainda, a criança, visualizar o castelo de brinquedo que ela tem em casa, ou o castelo que viu em um filme de terror. As cores, tamanho, estilo, detalhes são pessoais, se não houver uma descrição para o imaginário.

A imaginação e a criatividade são importantes características em um mundo que se transforma em velocidade como nunca antes aconteceu e que exige de todos nós respostas novas para novas situações, adaptações e flexibilidade ao ambiente e condições em constante modificação, como dizem Pedersen e Tortella (2015).

\section{FAZER PERGUNTAS AO TEXTO}

Fountas e Pinnell (2001) sugerem que os professores peçam que os alunos façam perguntas sobre o que leram, 
e que comparem as perguntas e respostas e as confrontem com outras leituras com a mesma temática. As autoras também sugerem que os alunos façam anotações durante a leitura e as usem, quando elaborarem perguntas sobre o texto lido.

Segundo Beers e Probst (2007, p.28), "a conversa monologa é autoritária e presume que o objetivo de quem escuta é concordar com ou aprender do orador". Os autores criticam a posição dos professores que não são abertos à dialogicidade. "A frase crítica [...] é 'se eles estiverem engajados. Nem toda conversa em sala de aula leva ao engajamento ou rigor. Conversar é uma ferramenta poderosa para melhorar a compreensão", complementam os autores. Para eles, perguntas que os professores fazem e cujas respostas já são conhecidas não são autênticas. E são essas perguntas que os professores fazem em sala de aula, ao contrário dos alunos.

Perguntas autênticas, ao contrário, são as perguntas para as quais você não sabe realmente a resposta. Quem responde entende que a sua contribuição ajuda verdadeiramente a formar o seu entendimento e fica muito mais favorável a se tornar engajado no diálogo. Infelizmente, a maior parte das pesquisas confirma que as conversas em sala de aula são majoritariamente monológicas, com o professor colocando 
os alunos defronte um grande número de perguntas pré-determinadas, que são, todos os alunos percebem, inautênticas. Pesquisas também mostram que em classes dialógicas, estudantes perguntam mais, e como resultado, aumenta o sucesso acadêmico (BEERS, PROBST, 2013, p.29).

Quando um professor termina de ler uma história, é comum ele perguntar: “Gostaram da história?”. Essa pergunta não é feita de forma imparcial, possivelmente o professor foi quem escolheu a história. Ele demonstra pelo olhar, tom de voz, entre outros comportamentos. Foi provavelmente ele quem escolheu o livro. O aluno responde quase que automaticamente "Sim". Outras perguntas podem seguir, como qual o nome do personagem, o que ele fez, quando aconteceu e onde. Perguntas objetivas, que não empolgam os envolvidos, muito menos o professor. Os alunos, por sua vez, se tiverem oportunidade de perguntar o que querem, podem fazer perguntas muito curiosas e criativas, como vimos em nossa pesquisa.

Schliesman (2012) diz que enquanto o leitor está lendo o texto, ele faz perguntas sobre o conteúdo, sobre as intenções do autor e do ilustrador, procurando informações para ampliar e aprofundar a compreensão do que pensava antes, durante e depois da leitura. Normalmente, ele as faz 
de forma silenciosa, e a oportunidade de trocar suas dúvidas com os colegas e professor pode ajudá-lo a compreender melhor e perceber o que não compreendeu.

Para Cash (2016), elaborar questões ajuda os alunos a entenderem o que leram e promove um pensamento de alto-nível em termos gerais. Ao elaborar perguntas, os alunos se tornam conscientes do seu próprio processo de aprendizagem.

\section{RESULTADOS}

Professores podem ajudar seus alunos ao ensinar estratégias e modos de leitura que facilitem a compreensão textual e a identificação das dificuldades que surgem durante a leitura.

A pesquisa-ação que trazemos nesse artigo buscou novos dados que pudessem contribuir com a prática docente, no que tange à leitura e ao uso de livros infantis em sala de aula, que promovessem a autorregulação da leitura. Pela perspectiva da Teoria Social Cognitiva e seus pressupostos, apresentamos estratégias e modos de leitura, bem como discutimos critérios de seleção de obras infantis para uso em sala de aula. Os resultados que buscamos foram levar ao conhecimento das professoras práticas possíveis de serem aplicadas em sala de aula e demonstrar que a seleção 
de obras infantis é fundamental na formação de leitores competentes, críticos e reflexivos.

Problematizamos se a exploração de estratégias de leitura e seleção de obras, em um curso de formação continuada, poderia auxiliar os professores participantes, em seu trabalho com leitura. Podemos afirmar, com base em pesquisas acadêmicas, que está comprovado que o uso de estratégias de leitura e a autorregulação da leitura melhoram o desempenho leitor do aluno (SCHUNK, 2001; SCHUNK, RICE, 1987; ZIMMERMAN, 2009; CASH, 2016; NASH-DITZEL, 2010; SOLÉ, 2008; HOUSAND, REIS, 2008). As professoras participantes dessa pesquisa concordam com essa afirmação, como exemplificamos: É possível, de forma lúdica, com essa técnica, ensinar os alunos. (F9E); No final, eles fizeram algumas inferências, contaram casos que conheciam, falaram de seus animais. Foi uma aula muito boa. (F16I)

O objetivo geral foi verificar se houve mudanças na prática dos professores quanto à exploração de modos, estratégias de leitura e seleção de obras no trabalho com leitura. Antes da formação, as professoras tinham as seguintes práticas: Leitura do professor, Leitura com questionamento, Leitura do aluno, Leitura de texto não literário, Textos com lição de 
moral. Nenhuma professora relatou as práticas de leitura em pares, leitura em voz alta pelo aluno, perguntas feitas pelos alunos, close reading, estratégias de antecipação, visualização, ativação de conhecimentos prévios, inferências. Mesmo que essas últimas tenham sido citadas como conhecidas por algumas das participantes, nenhuma as aplicava em sala de aula. Podemos afirmar que a maioria das professoras aplicou alguma ou todas as estratégias em algum momento da formação, e os dados apontam para a satisfação dessas docentes com as estratégias desenvolvidas com os alunos e, o que consideramos relevante, a participação efetiva dos alunos nas atividades propostas, segundo o relato das professoras: “Aprendi técnicas que desconhecia, meu olhar em relação ao livro mudou, e, apesar de serem técnicas para alunos leitores, a formadora trouxe vídeos e fotos de crianças pequenas aplicando as técnicas, o que me surpreendeu muito" (I5D*).

Atendemos aos nossos objetivos específicos: implementamos um modelo de formação continuada em leitura, apresentamos a autorregulação da leitura com base na TSC, discutimos a seleção das obras literárias para uso em sala de aula e analisamos em que medida as participantes aplicaram o conhecimento construído na formação. 
Quanto à seleção de obras, podemos constatar, pelas afirmações das professoras, que várias mudaram o olhar, entendendo que o livro não pode ser escolhido apenas pelo tema ou pela capa, sendo necessário avaliar sua qualidade literária.

Após um ano, as três professoras afirmaram ter mudado em algum sentido: quanto a ouvir mais seus alunos, quanto a aplicar a leitura em pares e em voz alta e, ainda, quanto a adotar a estratégia que faz parte do close reading, que é sublinhar.

Com a análise de dados, podemos afirmar que também encontramos os resultados seguintes: todas as professoras desconheciam a autorregulação da aprendizagem; a maioria das professoras não aprendeu critérios para seleção de obras na Formação Inicial e usa listas prontas para escolher o livro; a Formação de Professores é valorizada, mas as professoras encontram dificuldade em incluir novas práticas nos cronogramas; as professoras de Educação Infantil olham para a literatura infantil como deleite, sem cobranças de desempenho leitor; as modalidades de leitura em pares e em voz alta não eram usadas pelas professoras. Após a formação, foi a estratégia mais aplicada por elas; a leitura independente não é cogitada como uma atividade a ser 
planejada, considerando-se a leitura, ainda, como uma atividade para a eventualidade de sobrar algum tempo ao final da aula.

O close reading foi a estratégia que mais despertou o interesse de professoras do Fundamental I, embora necessite de mais tempo para seu exercício; estratégias de inferência, conexão, visualização e ativação de conhecimentos prévios eram as mais conhecidas. Não houve relatos de aulas para ensino dessas estratégias, antes da formação; algumas professoras que abriram espaço para os alunos fazerem perguntas se surpreenderam com o nível das questões formuladas; várias professoras afirmaram ter mudado o olhar em relação às obras literárias e ao uso de estratégias de leitura em sala de aula, o que, provavelmente, afetará a forma como seleciona e avalia as mesmas.

Durante toda a formação repetimos a importância de se considerar a qualidade literária do livro oferecido, assim como alertamos sobre algumas armadilhas que se escondem por trás do livro para criança. O nosso objetivo foi alcançado com essas professoras, que não mais escolherão um livro de forma "inocente", segundo relato das mesmas.

A mudança de olhar se explica em dois aspectos: 1) que agora as professoras acreditam que o uso de estratégias de 
leitura e da autorregulação da leitura ajuda a melhorar o desempenho leitor dos alunos, e 2) que a literatura infantil precisa ser valorizada e selecionada com base em critérios que atentem para a qualidade do texto, e não por aspectos materiais, como muitas relataram fazer, ao começo da pesquisa.

Essa mudança de olhar foi relatada em vários momentos, algumas vezes, revestida de surpresa pelas professoras, que não esperavam que seus alunos fossem capazes de fazer perguntas inteligentes ou compreender o texto lido com tal acurácia.

Também houve permanências, como as relatadas abaixo. Em uma formação de professores é natural que nem todos sejam afetados pela formação da mesma forma, como a própria teoria sociocognitiva explica pela tríade recíproca: Não teve mudança, no momento, não estou trabalhando diretamente com alunos, pois estou na coordenação (F15H*); Procedimento didático, talvez não. Mas o meu olhar sobre o desenrolar dos contatos diários e também atividades em leitura (F13G).

Essa pesquisa apresentou limitações que precisam ser mencionadas. Os participantes seriam todos de Ensino Fundamental, o que não se confirmou devido a contingências 
e necessidades da Secretaria de Educação. Preferimos mesclar professores a solicitar uma intervenção do órgão, que os incentivasse a participar. Como entre os alunos dos professores da formação havia desde crianças de 3 anos até adultos no EJA, houve restrições em relação à aplicação de estratégias de leitura, principalmente, pelos alunos que ainda não leem. Por outro lado, foi uma vivência muito rica para todos nós, essa troca de experiências diversificadas. Certamente, nos mostrou outras realidades, como o esforço dos alunos adultos que ainda não conseguem ler, sequer decodificar palavras. Esse novo contexto levou as pesquisadoras a buscarem aplicações das estratégias de leitura desde as crianças pequenas, com práticas que são amplamente aplicadas em outros países e que, só agora, estamos incluindo nas práticas escolares de nosso país.

Embora estejamos satisfeitas pela oportunidade de trabalhar com um grupo de professoras majoritariamente muito interessado e colaborativo, admitimos que ao longo do desenvolvimento dessa pesquisa, percebemos que o curto prazo de dois anos para a realização de um estudo que envolveu tantas variáveis, não foi o suficiente para que pudéssemos nos apropriar de todas as possibilidades no campo das estratégias de leitura. A duração de nove horas 
de formação é suficiente apenas para apresentar estratégias, e não para aplicação de exercícios e discussão efetiva da relação teoria e prática, tão desejada.

Considerando o curto prazo de duas horas para cada estratégia, é animador ouvir que as professoras ainda conseguiram empregar alguma(s) estratégia(s) que conheceram no curso. Seguramente, entendemos hoje que a leitura e a escrita não se explicam, aprendem ou ensinam sem considerar que o ensino da língua, a pedagogia e a psicologia andam de mãos dadas na construção desses saberes, de forma complementar.

A formação deveria ter sido mais longa, com exercícios em sala, particularmente do close reading, que é um procedimento mais complexo: "Precisávamos de mais tempo para fazer exercícios". O que confirmamos na formação seguinte, que não é parte dessa pesquisa, mas que foi elaborada considerando as críticas recebidas em relação a esse método, foi que um curso somente de close reading com exercícios em sala obteve uma compreensão muito maior por parte das participantes. Uma possibilidade plausível também é a de que a formadora estivesse melhor preparada nesse ano, e não o estivesse suficientemente capacitada para a formação no ano anterior, em se tratando dessa estratégia, que é muito mais complexa que as outras. 
Entendemos, também, que uma formação deve ser retomada com o passar do tempo, para que as dúvidas que surgiram possam ser esclarecidas, as experiências possam ser atualizadas e as práticas discutidas não caiam em desuso.

Para futuros estudos, ressaltamos a importância de que três dimensões sejam consideradas. Talvez, a dificuldade que temos em compreensão leitora se deva ao fato de não aprendermos que a leitura não é uma tarefa de execução simples. A leitura envolve processos cognitivos, psicológicos e ambientais.

\section{CONSIDERAÇÕES FINAIS}

Uma professora citou, durante a formação e repetiu, depois de um ano, que no curso de Pedagogia se aprende a ensinar a escrever, mas não se aprende a ensinar a ler, o que reflete nosso interesse e preocupação em trazer estratégias de leitura para essa pesquisa.

Com o caminhar dos encontros, percebemos que além das estratégias de leitura e da valorização da leitura de boas obras infantis, a pesquisa apresentava um bônus. Os encontros eram riquíssimos, e na socialização das experiências, a reflexão crítica se apresentava tanto para as professoras quanto para as pesquisadoras. Havia uma construção de saber coletivo, colaborativo e reflexivo que enriquecia a todos. 
As vivências nas formações de professores deixam marcas, formam, transformam professores e pesquisadores, além dos alunos, por meio dos saberes que os professores levam para o seu cotidiano. A TSC fundamentou essa pesquisa pela sua comprovada validade em incontáveis pesquisas. A autorregulação da aprendizagem e a autorregulação da leitura são caminhos que podem ajudar a aprofundar a compreensão leitora. A dimensão psicológica da leitura precisa ser considerada para que juntos, professores e alunos, possam aprender estratégias de leitura que ofereçam o apoio que os alunos precisam para tornarem-se leitores competentes e críticos, capazes de analisar o que o autor escreve e formular suas próprias opiniões.

O livro infantil não é um livro qualquer. Trata-se de literatura, alguns são, inclusive, ótimas leituras para todas as idades. O bom escritor não faz literatura menor para crianças. E o bom leitor sabe identificar quando um livro é boa literatura, que o faz refletir sobre si e sobre o mundo, promovendo uma experiência estética e sensível, sem mensagens fechadas e doutrinadoras.

A criança que aprende estratégias de leitura desde os anos inicias do fundamental, lerá com mais desenvoltura e prazer, o que fará de seus estudos um processo mais simples e eficiente. 


\section{REFERÊNCIAS}

ANDERSON, R. C.; FIELDING, Linda G.; WILSON, Paul T. (1988). "Growth in reading and how children spend their time outside of school". Reading Research Quarterly, 23, p.285-304.

ANJOS, Ana Maura Tavares; VIEIRA, Hamilton Perninck (2015). “Formação Docente e Literatura Infantil: contribuições para o desenvolvimento de leitores na educação infantil". Nuances: estudos sobre Educação Set/Dez, Presidente Prudente - SP, 26(3), p.303-322.

APPLEMAN, Deborah (2009). Critical encounters in high School English: Teaching literacy theory to adolescents. New York: Teachers College Press. BANDURA, Albert (1997). Self-efficacy: the exercise of control. New York, W. H. Freeman.

(1989). Social Cognitive Theory. In: R. Vasta (Ed.), Annals of child development. 6 . Six theories of child development. Greenwich, CT, JAI Press, p.1-60.

BEERS, Kylene; PROBST Robert E. (2013). NOTICE \& NOTE: strategies for close reading. Heinemann. PORTSMOUTH, NH, USA.

CASH, Richard M. (2016). Self-Regulation in the Classroom - Helping students learn how to learn. Free Spirit Publishing Inc., Golden Valley, Minneapolis, USA.

CASSIDY, Aideen (2007). Reading in Pairs. Start a peer tutoring program at your school. Junior Certificate School Programme Support Service. 2.ed. Dublin.

(1991) Becoming literate: the construction of inner control. Portsmouth, N. H. Heinemann Educational Bks.

CULLINAN, Bernice E. (1987). Children's Literature in the reading Program. Newark. International Reading Association.

(2000). Independent Reading and School Achievement. School Library Media Research, 3.

DUKE, N. K.; PEARSON, P.D. (2002). "Effective practices for developing reading comprehension". In: A. E. Farstrup, S. J. Samuels (Orgs.). What 
Research Has to Say about Reading Instruction. 3.ed. Newark: Int. Reading Association. p.205-242.

DURKIN, Dolores (1966). Children who read early. New York, teachers College $\mathrm{Pr}$.

FISH, Stanley (1982). Is there a text in this class? The authority of interpretative communities. Cambridge, MA: Harvard University Press.

FOUNTAS, Irene. C.; PINNELL, Gay Su (2001). Guiding Readers and Writers; teaching comprehension, Genre, and Content Literacy. Heinemann, NH, USA.

FRISON, Lourdes Maria Bragagnolo (2016). “Autorregulação da aprendizagem: abordagens e desafios para as práticas de ensino em contextos educativos". Campinas, Revista Educação PUC Camp Jan/Abr, 21(1), p.1-17.

GAMBRELL, Linda B.; MORROW, Lesley Mandel; PENNINGTON, Christina (2002). "Early Childhood and Elementary Literature-Based Instruction: Current Perspectives and Special Issues". Handbook of Reading Research: Volume III Reading Online 5(6), Fev.

GIMENO-SACRISTÁN, José (2008). A Educação que ainda é possível: ensaios sobre a cultura para a educação, Porto: Porto Ed. p.85-109.

GREANEY, Vincent (1980). "Factors related to amount and type of leisure reading". Reading Research Quarterly 15. p.337-57.

GREEN, Judith Lee; HARKER, Judith O. (1982). "Reading to children: a communicative process". In: Judith. A. Langer; M. Trika Smith-Burke (Eds). Reader meets author/Bridging the gap: a psycholinguistic and sociolinguistic perspective. Newark, p.196-212.

HINCHMAN, Kathleen A.; MOORE, David W. (2013). "Close reading: a cautionary interpretation". Journal of adolescent \& Adult Literacy 56(6), Mar., p.441-450.

HOUSAND, Angela; REIS, Sally M. (2008). "Self-regulated Learning in Reading: gifted pedagogy and Instructional Settings". In Journal of Advanced Academics. 20(1), p.108-136. 
KASTEN, Wendy C.; WILFONG, Lori G. (2007). "Encouraging Independent Reading: towards lifelong readers and learners". International Journal of Learning, 13(10).

KRAMER, Sonia; SOUZA, Solange Jobim (1996). História de professores: leitura, escrita e pesquisa em Educação. São Paulo: Ática.

LAJOLO, Marisa (2010). Do mundo da leitura para a leitura do mundo. 6.ed., São Paulo, Ática.

LEHMAN, Christopher; ROBERTS, Kate (2013). Falling in Love with Close Reading: Lessons for Analyzing Texts--and Life, Ed. Heinemann, USA.

NASH-DITZEL, Susan (2010). "Metacognitive reading Strategies can improve self-regulation". Journal of College Reading and Learning, 40(2).

NERUDA, Pablo (2008). Livro das Perguntas. São Paulo, SP: Cosac Naif. p.VLIV.

PEDERSEN, Simone (no prelo). A Literatura Infantil e a escola. Coleção Direitos Humanos em Educação. São Paulo, SP, Editora UFABC.

; TORTELLA, Jussara Cristina Barboza (2015a). "A Literatura infantil dialógica: promoção de experiências sensíveis e filosóficas". Revista Fermentario, 2(9), p.1-18.

RICHARDSON, Jane (2009). The next step in Guided Reading: K-8. Scholastic, USA.

ROSÁRIO, Pedro; PACHECO, Mónica; ALLMEIDA, S. Leandro; GUIMARÃES, Carina (2001). "Como estudam os alunos de elevado rendimento acadêmico? Uma análise centrada nas estratégias de auto-regulação". Sobredotação 2(1), p.103-116.

ROSENBLATT, Louise (1978). The reader, the text, the poem: The transactional theory of the literacy work. Carbondale: Southern Illinois University Press.

ROSER, Nancy; MARTINEZ, Miriam (1985). "Roles adults play in preschoolers' response to Literature". Language Arts, 62, p.485-490.

SANTOS, Acácia A. Angeli dos; SUEHIRO, Adriana C. B.; OLIVEIRA, Katya Luciane de (2004). "Habilidades em compreensão de leitura: um estudo com alunos de psicologia". Estudos de Psicologia (Natal), 2, p.29-42. 
SCHOLASTIC (2014). The Kids \& Family Reading Report: Fifth Edition. USA. SCHLIESMAN, Megan. Reading to Understand: Children's Book to Use with Comprehension Streets. Cooperative Children's book Center (CCBC). School of Education, University of Wisconsin-Madison. In https://ccbc. education.wisc.edu/books/detailListBooks.asp?idBookLists=201 Acesso em 13.Jul.2016.

SCHUNK, Dale H. (2001). "Social cognitive theory and self-regulated learning". In: Zimmerman, Barry. J. \& Schunk, Dale H. (Eds.) Self-regulated Learning and Academic Achievement: Theoretical Perspectives. Mahwah, NJ. Lawrence Erlbaum Associates.

; RICE, Jo Mary (1987). "Enhancing comprehension skill and selfefficacy with strategy value information". Journal of Reading Behaviour, 19, p.285-302.

SIMON, Cathy Allen (2016). Strategy Guide: Make Connections. In http:// www.readwritethink.org/professional-development/strategy-guides/ making-connections-30659.html Acesso em 12.Jul.2016.

SIMÕES, Cyntia Graziella Guizelim; SOUZA, Renata Junqueira de (2008). "Estratégias de leitura: uma alternativa para o início da educação literária". Álabe, (10), p.1-23.

SISSON, Diana; SISSON, Betsy (2014). Close reading in Elementary School: bringing Readers and texts together. New York, Routledge.

SMITH, Frank (1999). Leitura significativa. Porto Alegre. Artes Médicas. SNOW, Catherine; GRIFFIN, Peg \& BURNS, M. Susan (2005). Knowledge to support the teaching of reading: Preparing teachers for a changing world. SF, CA: Jossey-Bass.

SOLÉ, Isabel (2008). Estratégias de Leitura. 6. Ed. Porto Alegre. Artmed. SOLÉ, Melanie; DIPARDO, Anne (2008). “English Education Research and classroom practice: New directions for new times". Review Research in Education, 32(1), p.62-108.

ZIMMERMAN, Barry. J. (1989). “A social cognitive view of self-regulated academic learning". Journal of Educational Psychology, 81(3), p.329-339. 
(2002). "Motivational sources and outcomes of self-regulated learning and performance". In: Becoming a Self-Regulated Learner: an overview. Theory into Practice, 41(2) Spring, College of Education, The Ohio University.

(2009). "Theories of self-regulated learning achievement: An overview and analysis". In: ZIMMERMAN, B. J.; SCHUNK, D. H. (Eds.). Self-Regulated Learning and Academic Achievement. 2.ed. New York: Routledge, USA, p.1-38.

; SCHUNK, Dale H. (Eds.) (2011). Handbook of self-regulation of learning and perspectives. Routledge, New York, USA, p.49-64.

; BANDURA, Albert (1994). "Impact of Self-regulatory Influences on Writing Course Attainment". American Educational Research Journal, $31(4)$.

; MARTINEZ-PONS, Manuel (1988). "Development of a structured interview for assessing student use of self-regulated learning strategies". American Educational Research Journal, EUA, 23(4), p.614-628.

Simone Alves Pedersen é Doutoranda em Educação pela Universidade Estadual Paulista Júlio de Mesquita Filho - Rio Claro. Email: s.pedersen@ uol.com.br.

Jussara Cristina Barboza Tortella é Doutora em Educação pela Pontifícia Universidade Católica de Campinas. Email: jussaratortela@gmail.com. 